\title{
Origin of Difference in Photocatalytic Activity of ZnO (002) Grown on a- and c-Face Sapphire
}

\author{
Guoqiang Li, ${ }^{1,2}$ Bingyang Sun,, ${ }^{1,2}$ Yali Wang, ${ }^{1,2}$ Zhou Wu, $^{1,2}$ and Weifeng Zhang ${ }^{1}$ \\ ${ }^{1}$ Key Laboratory of Photovoltaic Materials of Henan Province and School of Physics \& Electronics, \\ Henan University, Kaifeng 475004, China \\ ${ }^{2}$ Institute of Physics for Microsystems, Henan University, Kaifeng 475004, China \\ Correspondence should be addressed to Weifeng Zhang; wfzhang@henu.edu.cn
}

Received 9 October 2013; Revised 5 February 2014; Accepted 10 February 2014; Published 12 March 2014

Academic Editor: Pramod H. Borse

Copyright (C) 2014 Guoqiang Li et al. This is an open access article distributed under the Creative Commons Attribution License, which permits unrestricted use, distribution, and reproduction in any medium, provided the original work is properly cited.

\begin{abstract}
The oriented (002) ZnO films were grown on a- and c-face sapphire by pulsed laser deposition. The X-ray diffraction analysis revealed that the oriented (002) $\mathrm{ZnO}$ films were epitaxially grown on the substrate successfully. The sample on a-face sapphire had higher crystal quality. However, the photocatalytic activity for Rhodamine B degradation of $\mathrm{ZnO}$ film on c-face sapphire was higher than that on a-face sapphire. The Raman spectrum and XPS analysis suggested that the sample on a-face sapphire had higher concentration of defects. The result of the contact angle measurement revealed that the sample on c-face sapphire had higher surface energy. And the investigation of the surface conductance implied that the higher light conductance was helpful for the photocatalytic activity.
\end{abstract}

\section{Introduction}

Semiconductor photocatalysis has attracted many attentions due to the extensive potential applications in renewable energy production and environmental remediation [1]. Many semiconductor oxides were evaluated for the photocatalytic activity for water splitting or organic compound decomposition [2-5]. Among the binary metal oxide photocatalysts, $\mathrm{ZnO}$ was studied extensively, especially for the samples with nanoplate, nanorod, microrod, and dumbbell-shape morphology [6-10]. Recently, $\mathrm{ZnO}$ photoanodes with the (100) preferential orientation have been shown to generate hydrogen under solar photon illumination [11]. However, the key factor of the given plane impacting the photocatalytic activity was not addressed due to the limit of the samples. This question would help us understand and improve the photocatalytic activity of the sample exposed one certain facet.

The $\mathrm{ZnO}$ sample exposed crystal plane was controllable when it was fabricated by pulsed laser deposition (PLD) via selecting the proper substrate [12-15]. The $\mathrm{ZnO}$ with the (001) plane could be grown on both a- and c-face sapphire $[13,15]$. Although their crystal plane was the same, they often exhibit different physical and chemical properties [16]. Consequently, in this study, the $\mathrm{ZnO}$ samples oriented (002) plane was prepared on a-plane and c-plane sapphire by PLD and investigated for photocatalytic activity. The sample on cplane sapphire showed higher activity than that on a-plane sapphire. The observations revealed that the crystallinity and defects did not affect the photocatalytic activity positively, while the surface free energy and surface conductance had the positive effect.

\section{Experimental}

The $\mathrm{ZnO}$ thin films were deposited on a-plane and c-plane sapphire substrates by PLD. The fabrication conditions for the $\mathrm{ZnO}$ layer were as follows: laser repetition rate $3 \mathrm{~Hz}$, target and substrate distance $50 \mathrm{~mm}$, laser energy $300 \mathrm{~mJ}, \mathrm{O}_{2}$ partial pressure about $2.0 \times 10^{-2} \mathrm{~Pa}$, substrate temperature $873 \mathrm{~K}$, and deposited time $0.5 \mathrm{~h}$.

The thickness of $\mathrm{ZnO}$ thin films grown on a-plane and c-plane sapphire was estimated with the aid of ellipsometer (type II, Taijing Tuopu Co., China). The thickness of $\mathrm{ZnO}$ thin film grown on a-plane and c-plane sapphire was estimated 


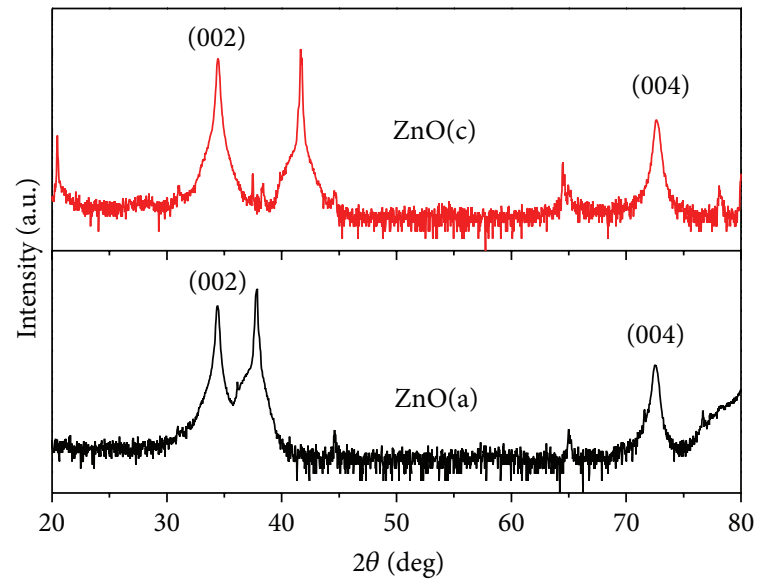

(a)

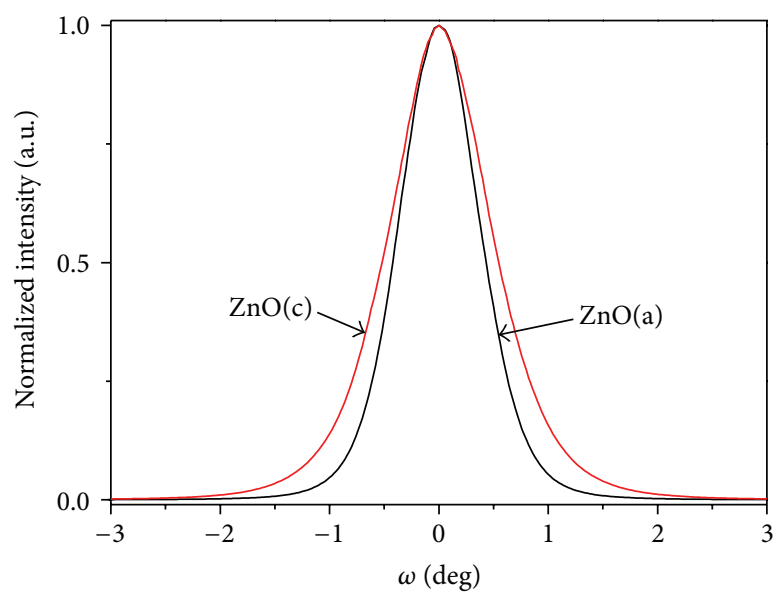

(b)

FIGURE 1: X-ray diffraction (XRD) patterns (a) and $\omega$-scan spectra (b) of $\mathrm{ZnO}$ thin films grown on a-plane and c-plane sapphire.

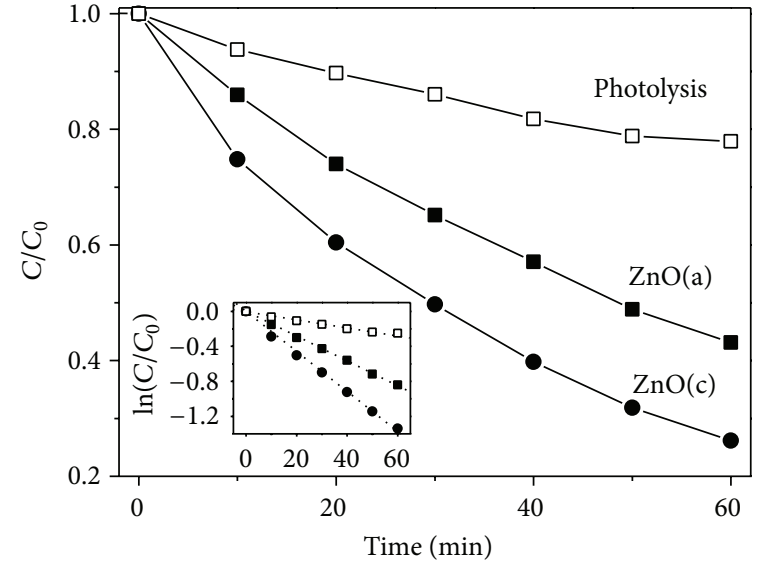

(a)

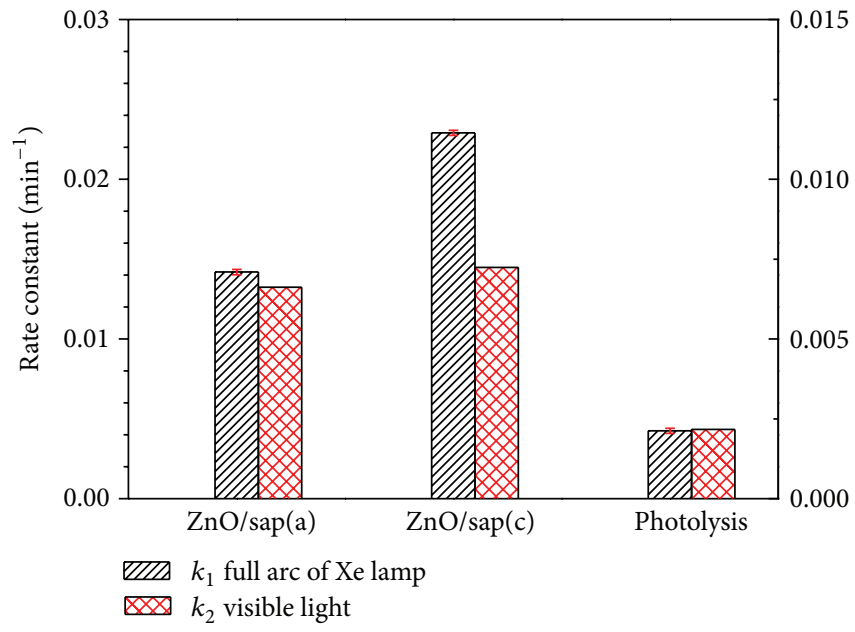

(b)

Figure 2: (a) Variation in $\mathrm{RhB}$ concentration over $\mathrm{ZnO}$ thin films grown on a-plane and c-plane sapphire; the inset of a is the plot of first order kinetics. (b) Rate constant in the degradation of $\mathrm{RhB}$ over $\mathrm{ZnO}$ thin films grown on a-plane and c-plane sapphire under full arc and visible light irradiation of Xe lamp.

to be $\sim 270 \mathrm{~nm}$. The crystal structures of samples were determined by an X-ray diffractometer (DX-2500 diffractometer, Fangyuan) with $\mathrm{Cu} K \alpha$ radiation $(\lambda=0.154145 \mathrm{~nm})$ in $\theta-2 \theta$ mode. The carrier density was obtained from the Hall measurement. The surface morphology was observed by atomic force microscopy (AFM, SPA400, Japan). The transmittance spectrum was recorded with a UV-Vis spectrophotometer (Varian Cary 5000) using the air as the reference and transformed to the absorption spectra automatically. In the case of X-ray photoelectron spectroscopy (Thermo ESCALAB 250, USA), an Al anode with a monochromator was used to reduce the background signal. The binding energy was referenced to the $\mathrm{C}$ 1s peak taken at $284.8 \mathrm{eV}$. Raman scattering spectrum was measured using a laser Raman spectrophotometer (RM1000, Renishaw). Surface conductivity was measured on the samples covered by the plane fork electrode with the fork width of $0.1 \mathrm{~mm}$ under full arc of $450 \mathrm{~W}$ Xe lamp irradiation.

The photocatalytic activities of the as-prepared samples were evaluated by the Rhodamine $\mathrm{B}(\mathrm{RhB})$ under full arc and visible light irradiation of $300 \mathrm{~W}$ Xe lamp. The photocatalytic reaction was carried out over the sample with the area of $1 \mathrm{~cm}^{2}$ in a $1 \mathrm{~mL} \mathrm{RhB}$ solution in a sealed quartz cuvette with the light path length of $3 \mathrm{~mm}$. There was no stirring during reaction. The initial concentration of $\mathrm{RhB}$ solution was about $10 \mathrm{mg} \cdot \mathrm{L}^{-1}$. After $30 \mathrm{~min}$ dark reaction, the variation in $\mathrm{RhB}$ concentration was in situ recorded in the interval of $10 \mathrm{~min}$ 


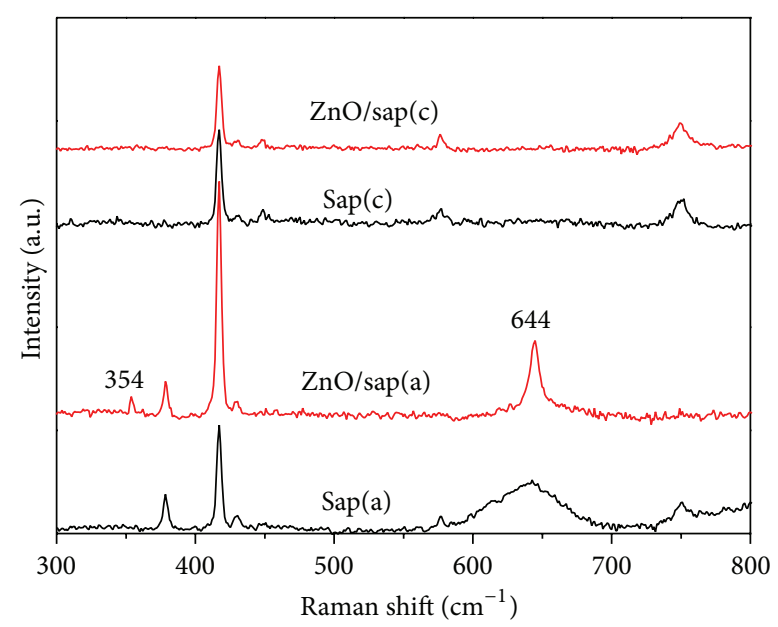

FIGURE 3: Raman spectra obtained from $\mathrm{ZnO}$ thin films grown on a-plane and c-plane sapphire.

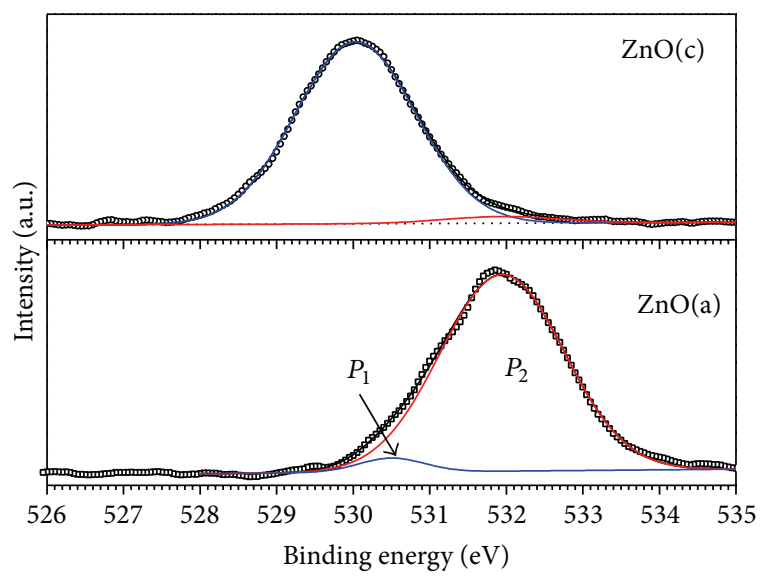

FIgURE 4: O 1s XPS line obtained from $\mathrm{ZnO}$ thin films grown on a-plane and c-plane sapphire.

using a UV-Vis spectrophotometer (UV2550, Shimadzu, Japan) by measuring the absorption spectrum.

\section{Results and Discussion}

The X-ray diffraction (XRD) patterns of $\mathrm{ZnO}$ thin films grown on a-plane and c-plane sapphire were shown in Figure 1(a). Obviously, the oriented $\mathrm{ZnO}$ films along with (002) were fabricated successfully. The lattice parameter along the c-axis for this $\mathrm{ZnO}$ film on a- and c-plane sapphire was 5.2096 and $5.2022 \AA$ Á, respectively. For simplicity, hereafter, the samples on a-plane and c-plane sapphire were denoted as $\mathrm{ZnO}(\mathrm{a})$ and $\mathrm{ZnO}(\mathrm{c})$, respectively. The crystal qualities for the prepared samples are characterized by the $\omega$-scan spectra, as shown in Figure 1(b). The full width at half maximum (FWHM) is $0.86^{\circ}$ for $\mathrm{ZnO}(\mathrm{a})$ and $1.08^{\circ}$ for $\mathrm{ZnO}(\mathrm{c})$, which is close to the previous results obtained from the samples prepared by PLD [17]. The smaller FWHM of ZnO(a) indicated that its crystal quality was better than that of

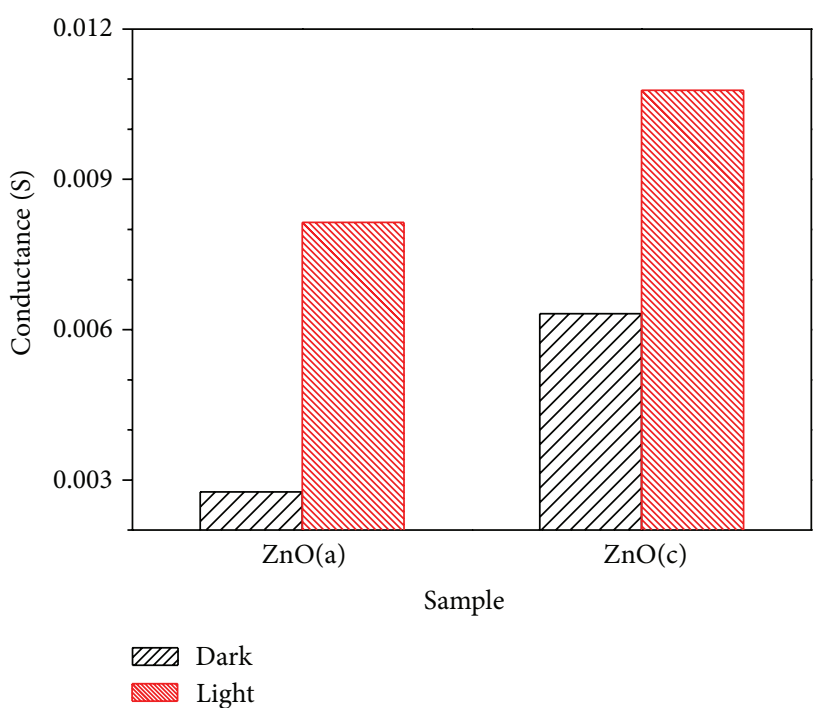

FIGURE 5: Conductance of $\mathrm{ZnO}$ thin films grown on a-plane and cplane sapphire.

$\mathrm{ZnO}(\mathrm{c})$. The a-plane sapphire was nonpolarized, while the c-plane was polarized. The polarized substrate would offer an electric field during the deposition. The $\mathrm{ZnO}$ (002) was polarized plane. Therefore, the fact of better crystal quality of $\mathrm{ZnO}$ (a) was considered to be caused by the polarization of substrate.

Photocatalytic activity for the decomposition of RhB in an aqueous solution was evaluated in the presence of $\mathrm{ZnO}$ films under full arc and visible light irradiation of Xe lamp. Figure 2(a) is the variation in $\mathrm{RhB}$ concentration which was obtained from monitoring the main peak at $\sim 554 \mathrm{~nm}$. The $74 \% \mathrm{RhB}$ was degraded by $\mathrm{ZnO}$ (c) after one hour irradiation, while $57 \%$ by $\mathrm{ZnO}(\mathrm{a})$. Additionally, the self-degradation of $\mathrm{RhB}$ was about $22 \%$. When the reagent solution was dilute, the reaction rate $(r)$ could be expressed as $r=k C$, where $k$ is the apparent rate constant and $C$ is the instantaneous concentration of the reactant. The plot of $\ln \left(C / C_{0}\right)$ versus time was shown in the inset of Figure 2(a). The reactions exhibited the first order reaction kinetics for $\mathrm{ZnO}(\mathrm{a})$ and $\mathrm{ZnO}(\mathrm{c})$. Consequently, the apparent rate constant was used to compare the photocatalytic activity. Figure 2(b) shows the apparent rate constant for $\mathrm{RhB}$ under full arc $\left(k_{1}\right)$ and visible light irradiation $\left(k_{2}\right)$, where the apparent rate constant under visible light irradiation was applied to characterize the selfsensitized degradation of $\mathrm{RhB}$. The visible light activity was considered to be caused by the self-sensitized degradation of $\mathrm{RhB}$ because $\mathrm{ZnO}$ was a UV active photocatalyst. From Figure 2(b), it could be seen that the activity under full arc irradiation was larger than that under visible light, indicating that the $\mathrm{RhB}$ degradation was really related to the light excitation. Both $\mathrm{ZnO}$ samples showed higher activity than the photolysis, demonstrating that the $\mathrm{ZnO}$ played an important role in the degradation of $\mathrm{RhB}$. The proportion of the self-sensitized degradation of $\mathrm{RhB}$ in the total degradation was very important to understand the real photocatalytic activity of $\mathrm{ZnO}$. The ratio of $k_{2}$ to $k_{1}$ was used to estimate 


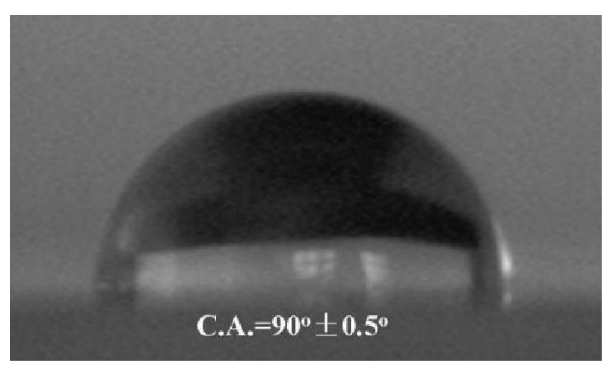

(a)

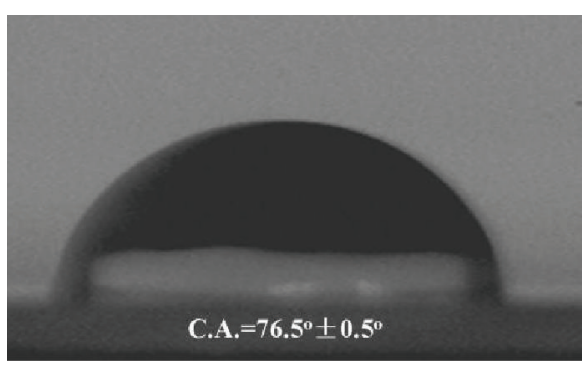

(b)

FIGURE 6: Contact angle obtained from $\mathrm{ZnO}$ thin films grown on a-plane and c-plane sapphire.

the proportion of the self-sensitized degradation of $\mathrm{RhB}$ in the total degradation. The larger $k_{2} / k_{1}$ ratio implied the higher proportion of the self-sensitized degradation of $\mathrm{RhB}$, indicating the lower activity of $\mathrm{ZnO}$. The ratio of $k_{2}$ to $k_{1}$ for $\mathrm{ZnO}$ (c) was $31 \%$, which was the smallest compared to $46 \%$ for $\mathrm{ZnO}(\mathrm{a})$ and $51 \%$ for photolysis, implying that the $\mathrm{RhB}$ degradation due to $\mathrm{ZnO}(\mathrm{c})$ excitation was dominant in the total degradation.

The photocatalytic activity was affected by the bulk and surface properties. $\mathrm{ZnO}$ (a) had a better crystallinity than $\mathrm{ZnO}(\mathrm{c})$, revealing that the crystallinity was not the key factor to determine the photocatalytic activity in these samples. Also the optical band gap estimated from the absorption spectra was the same, but the absorption coefficient of $\mathrm{ZnO}(\mathrm{c})$ was larger than that of $\mathrm{ZnO}(\mathrm{a})$. The average roughness was estimated to be $1.1 \mathrm{~nm}$ for sample on a-face sapphire and $8.6 \mathrm{~nm}$ for sample on c-face sapphire. The sample on cface sapphire showed higher activity than that on a-face sapphire, indicating that the larger roughness and absorption coefficient were helpful for photocatalytic activity.

To obtain the key factors to impact the photocatalytic activity of $\mathrm{ZnO}$ (001) plane, we had examined the optical properties, surface properties, and electrical property of the prepared samples.

The Raman spectra were shown in Figure 3. Except for the peaks of substrate, the new peaks at $644 \mathrm{~cm}^{-1}$ and $354 \mathrm{~cm}^{-1}$ were observed in $\mathrm{ZnO}(\mathrm{a})$, while now new peak was obtained in $\mathrm{ZnO}$ (c). The peak at $644 \mathrm{~cm}^{-1}$ was caused by the defects, such as the $\mathrm{Zn}$ interstitials or oxygen vacancies [18]. The appearance of $644 \mathrm{~cm}^{-1}$ peak indicated that some effects existed in $\mathrm{ZnO}(\mathrm{a})$. And almost the same profile between the $\mathrm{ZnO}(\mathrm{a})$ and substrate implied that few defects were in $\mathrm{ZnO}(\mathrm{c})$.

The O 1s XPS line was usually used to characterize the existence of oxygen vacancy [19]. The O 1s XPS line obtained from $\mathrm{ZnO}(\mathrm{a})$ and $\mathrm{Zn}(\mathrm{c})$ was shown in Figure 4. The $\mathrm{O} 1 \mathrm{~s}$ region was fitted by two peaks with Gauss distribution, and these peaks located at 531.95 and $530.5 \mathrm{eV}$ for $\mathrm{ZnO}$ (a) and at 531.95 and $530.03 \mathrm{eV}$ for $\mathrm{ZnO}(\mathrm{c})$. The fitting of $\mathrm{O} 1 \mathrm{~s}$ region with two-peak contribution indicated that at least two kinds of oxygen species were presented in the near surface domain of the $\mathrm{ZnO}$ films. The peak $P_{1}$ at about $530 \mathrm{eV}$ was due to crystal lattice oxygen of $\mathrm{ZnO}$, while the peak $P_{2}$ at about $532 \mathrm{eV}$ was due to chemisorbed oxygen on the film surfaces $[20,21]$. These previous studies implied that the surface adsorbed oxygen could hide the signal of crystal lattice oxygen [21]. The more the adsorbed oxygen was, the weaker the signal of crystal lattice oxygen was. Moreover, the intensity of the peak $P_{2}$ was connected to the concentration of oxygen vacancies [19]. Consequently, we considered that the amount of the defects in $\mathrm{ZnO}$ (a) was more than that in $\mathrm{ZnO}(\mathrm{c})$. Taking into account the results of Raman spectra, it seems that the defects are not positive to the photocatalytic activity.

Surface conductivity, especially under light irradiation, was very important to the photoelectric processing in semiconductor. The surface conductivity in the dark and under full arc of Xe lamp irradiation was measured. The surface conductivity under light irradiation was larger than that in the dark, as shown in Figure 5, which was consistent with the previous report [22]. Moreover, the rate constants for $\mathrm{RhB}$ degradation increased with the increase in the conductivity under light irradiation. The light irradiation would bring much larger electron mobility than that in the dark [22]. The photocatalytic reaction contained light absorption, generation of e-h pairs, charge transfer, and chemical reaction on surface, apart from all kinds of recombination. After the generation of e-h pairs coming from the light excitation, the electron would transfer to the surface of photocatalyst. The higher surface conductance would be helpful to the charge transfer. According to the above description, it was thus reasonable to understand that the sample with the larger surface conductivity showed the higher activity.

Surface free energy could be evaluated from the contact angle measurement because the specimens did not have the special microstructure. Generally, the smaller the contact angle is, the higher the surface free energy is. The results of contact angle measurement for all the tested samples were shown in Figure 6. The contact angle for $\mathrm{ZnO}$ (a) was $90^{\circ} \pm 0.5^{\circ}$ and that for $\mathrm{ZnO}$ (c) was $76.5^{\circ} \pm 0.5^{\circ}$. The smaller contact angle for $\mathrm{ZnO}(\mathrm{c})$ revealed that it had higher surface free energy. $\mathrm{Bi}$ et al. proposed that the higher photocatalytic activity of $\mathrm{Ag}_{3} \mathrm{PO}_{4}$ could be obtained in the sample that exposed the face with the higher surface energy [23]. Therefore, the surface free energy was considered to be closely relative to the photocatalytic activity. 


\section{Conclusions}

The $\mathrm{ZnO}$ samples oriented (002) plane was prepared successfully on a-plane and c-plane sapphire by PLD. The ZnO on c-plane sapphire showed higher activity than that on aplane sapphire. The crystallinity and amount of defects did not have positive contribution on the photocatalytic activity, but the higher surface free energy and conductance had positive effects on the photocatalytic activity. The quantitative relationship between these factors and activity was being investigated.

\section{Conflict of Interests}

The authors declare that there is no conflict of interests regarding the publication of this paper.

\section{Acknowledgments}

This work was supported by the National Natural Science Foundation of China (21103041), National Postdoctoral Funding (2011M500786), and Program for Innovative Research Team in Science and Technology in University of Henan Province (IRTSTHN) (Grant no. 2012 IRTSTHN004).

\section{References}

[1] N. Serpone and A. V. Emeline, "Semiconductor photocatalysis-past, present, and future outlook," Journal of Physical Chemistry Letters, vol. 3, no. 5, pp. 673-677, 2012.

[2] A. Kudo and Y. Miseki, "Heterogeneous photocatalyst materials for water splitting," Chemical Society Reviews, vol. 38, no. 1, pp. 253-278, 2009.

[3] G. Liu, J. C. Yu, G. Q. Lu, and H.-M. Cheng, "Crystal facet engineering of semiconductor photocatalysts: motivations, advances and unique properties," Chemical Communications, vol. 47, no. 24, pp. 6763-6783, 2011.

[4] F. E. Osterloh, "Inorganic nanostructures for photoelectrochemical and photocatalytic water splitting," Chemical Society Reviews, vol. 42, pp. 2294-2320, 2013.

[5] H. Tong, S. Ouyang, Y. Bi, N. Umezawa, M. Oshikiri, and J. Ye, "Nano-photocatalytic materials: possibilities and challenges," Advanced Materials, vol. 24, no. 2, pp. 229-251, 2012.

[6] E. S. Jang, J.-H. Won, S.-J. Hwang, and J.-H. Choy, "Fine tuning of the face orientation of $\mathrm{ZnO}$ crystals to optimize their photocatalytic activity," Advanced Materials, vol. 18, no. 24, pp. 3309-3312, 2006.

[7] N. Kislov, J. Lahiri, H. Verma, D. Y. Goswami, E. Stefanakos, and M. Batzill, "Photocatalytic degradation of methyl orange over single crystalline $\mathrm{ZnO}$ : orientation dependence of photoactivity and photostability of $\mathrm{ZnO}$," Langmuir, vol. 25, no. 5, pp. 33103315, 2009.

[8] A. Mclaren, T. Valdes-Solis, G. Li, and C. T. Shik, "Shape and size effects of $\mathrm{ZnO}$ nanocrystals on photocatalytic activity," Journal of the American Chemical Society, vol. 131, no. 35, pp. 1254012541, 2009.

[9] M. Y. Guo, A. M. C. Ng, F. Liu et al., "Effect of native defects on photocatalytic properties of ZnO," Journal of Physical Chemistry C, vol. 115, no. 22, pp. 11095-11101, 2011.
[10] J. Gupta, K. C. Barick, and D. Bahadur, "Defect mediated photocatalytic activity in shape-controlled $\mathrm{ZnO}$ nanostructures," Journal of Alloys and Compounds, vol. 509, no. 23, pp. 67256730, 2011.

[11] R. Dom, H. G. Kim, and P. H. Borse, "Efficient hydrogen generation over (100)-oriented $\mathrm{ZnO}$ nanostructured photoanodes under solar light," CrystEngComm, 2014.

[12] C. Bundesmann, N. Ashkenov, M. Schubert et al., "Raman scattering in $\mathrm{ZnO}$ thin films doped with $\mathrm{Fe}, \mathrm{Sb}, \mathrm{Al}, \mathrm{Ga}$, and $\mathrm{Li}$," Applied Physics Letters, vol. 83, no. 10, pp. 1974-1976, 2003.

[13] S. Choopun, R. D. Vispute, W. Noch et al., "Oxygen pressuretuned epitaxy and optoelectronic properties of laser-deposited ZnO films on sapphire," Applied Physics Letters, vol. 75, no. 25, pp. 3947-3949, 1999.

[14] J.-M. Chauveau, P. Venńgùs, M. Laügt, C. Deparis, J. ZunigaPerez, and C. Morhain, "Interface structure and anisotropic strain relaxation of nonpolar wurtzite $(11 \overline{2} 0)$ and $(10 \overline{1} 0)$ orientations: $\mathrm{ZnO}$ epilayers grown on sapphire," Journal of Applied Physics, vol. 104, no. 7, Article ID 073535, 2008.

[15] J. F. Muth, R. M. Kolbas, A. K. Sharma, S. Oktyabrsky, and J. Narayan, "Excitonic structure and absorption coefficient measurements of $\mathrm{ZnO}$ single crystal epitaxial films deposited by pulsed laser deposition," Journal of Applied Physics, vol. 85, no. 11, pp. 7884-7887, 1999.

[16] A. Yamamoto, Y. Moriwaki, K. Hattori, and H. Yanagi, "A comparative study of photoluminescence of $\mathrm{Zn}$-polar and Opolar faces in single crystal $\mathrm{ZnO}$ using moment analysis," Applied Physics Letters, vol. 98, no. 6, Article ID 061907, 2011.

[17] S. L. King, J. G. E. Gardeniers, and I. W. Boyd, "Pulsed-laser deposited $\mathrm{ZnO}$ for device applications," Applied Surface Science, vol. 96-98, pp. 811-818, 1996.

[18] C. L. Du, Z. B. Gu, Y. M. You et al., "Resonant Raman spectroscopy of (Mn,Co)-codoped $\mathrm{ZnO}$ films," Journal of Applied Physics, vol. 103, no. 2, Article ID 023521, 2008.

[19] J. Wang, Z. Wang, B. Huang et al., "Oxygen vacancy induced band-gap narrowing and enhanced visible light photocatalytic activity of ZnO," ACS Applied Materials \& Interfaces, vol. 4, no. 8, pp. 4024-4030, 2012.

[20] Y.-P. Du, Y.-W. Zhang, L.-D. Sun, and C.-H. Yan, "Efficient energy transfer in monodisperse Eu-doped $\mathrm{ZnO}$ nanocrystals synthesized from metal acetylacetonates in high-boiling solvents," Journal of Physical Chemistry C, vol. 112, no. 32, pp. 12234-12241, 2008.

[21] D. Lee, O. Kwon, J. Song et al., "Effects of ZnO:Al films on CIGS PV modules degraded under accelerated damp heat," Solar Energy Materials and Solar Cells, vol. 105, pp. 15-20, 2012.

[22] C. H. Swartz, "Transport and surface conductivity in $\mathrm{ZnO}$," Journal of Materials Research, vol. 27, no. 17, pp. 2205-2213, 2012.

[23] Y. Bi, S. Ouyang, N. Umezawa, J. Cao, and J. Ye, "Facet effect of single-crystalline $\mathrm{Ag}_{3} \mathrm{PO}_{4}$ sub-microcrystals on photocatalytic properties," Journal of the American Chemical Society, vol. 133, no. 17, pp. 6490-6492, 2011. 

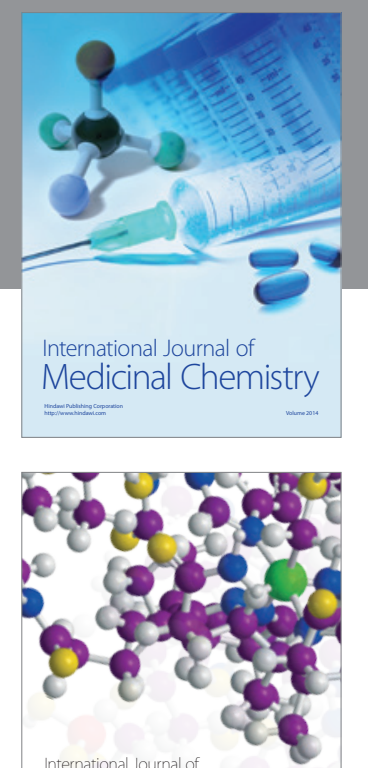

\section{Carbohydrate} Chemistry

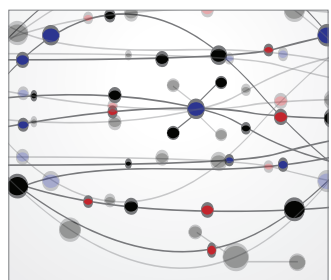

The Scientific World Journal
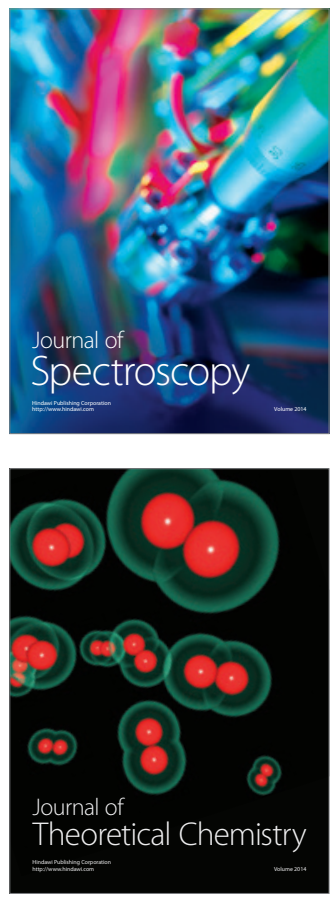
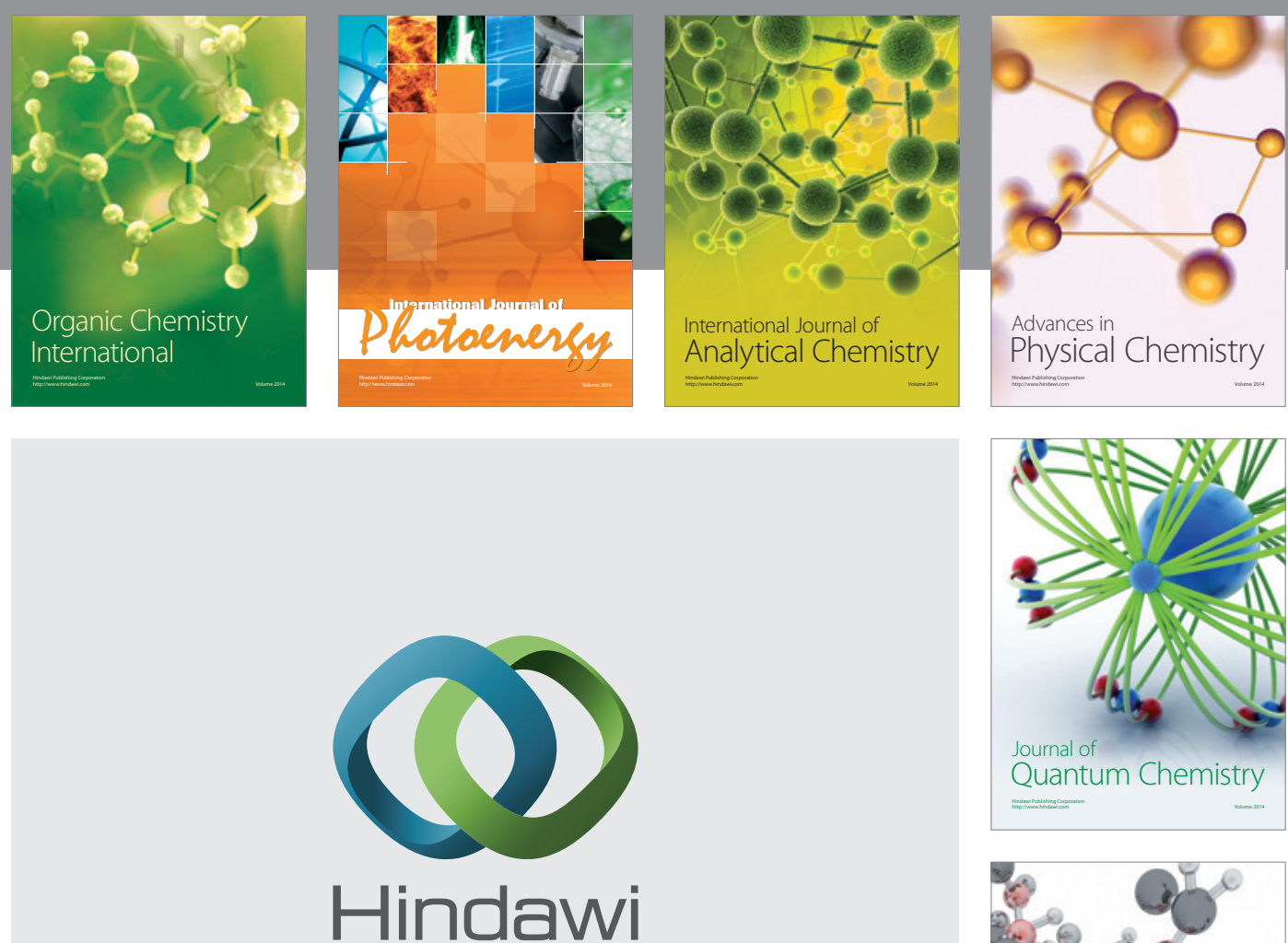

Submit your manuscripts at

http://www.hindawi.com

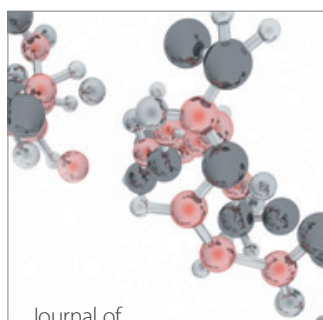

Analytical Methods

in Chemistry

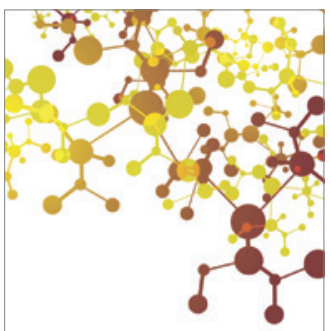

Journal of

Applied Chemistry

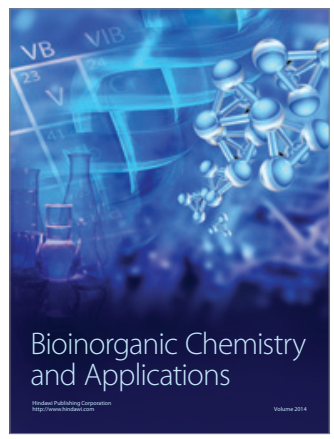

Inorganic Chemistry
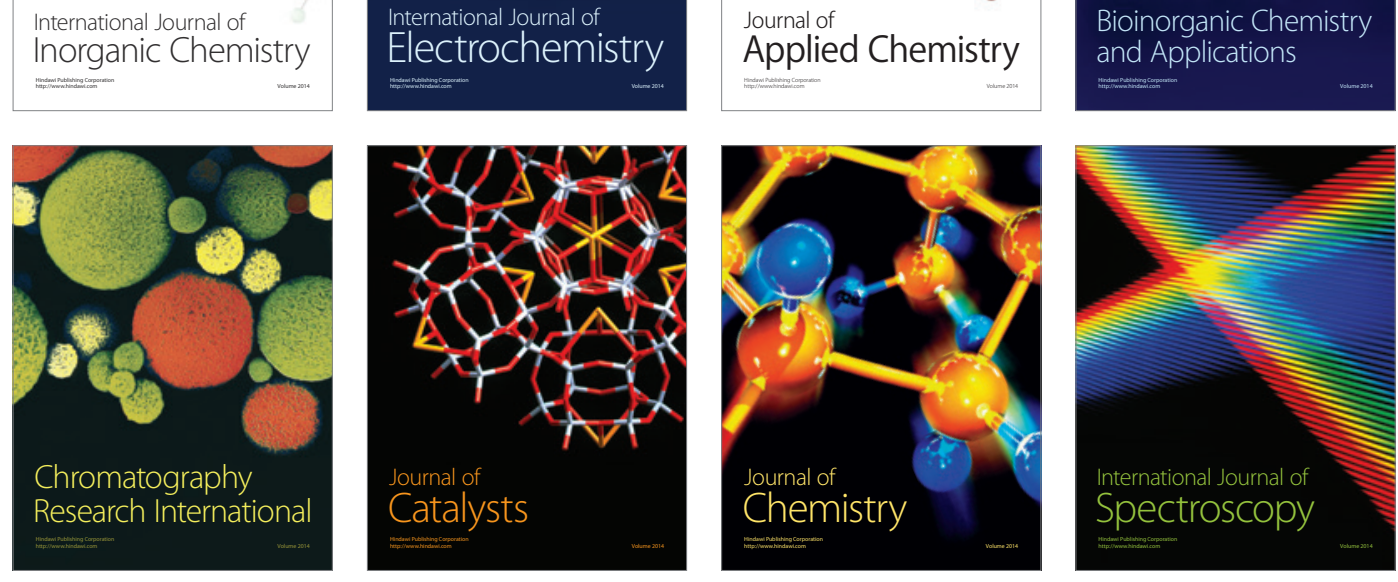